\title{
EL EJERCICIO DE LA LIBERTAD Y LA APTITUD PARA DECIDIR DE LAS PERSONAS RECLUIDAS EN UNA PRISIÓN
}

\author{
The exercise of freedom and the ability to decide of the inmates in a prison
}

\author{
Maximiliano Hernández Cuevas ${ }^{*}$
}

\begin{abstract}
Resumen. El artículo centra el debate en el tema de la libertad de conciencia de los detenidos en las prisiones mexicanas, derecho de las personas que es vulnerado por los programas de rehabilitación o reinserción social y la legislación correspondiente, incluidos algunos instrumentos legales de carácter internacional sobre derechos humanos. Se exponen argumentos dirigidos a demostrar que tanto la prescripción jurídica de trabajos forzados, como la práctica de diagnósticos de personalidad, resultan trasgresiones al derecho de los reclusos a decidir en torno a cuestiones fundamentales sobre su vida, interés subjetivo que debe ser protegido aun en la vida de reclusión.
\end{abstract}

Palabras clave: prisiones, derechos humanos, libertad de conciencia, reinserción social.

\begin{abstract}
The article focuses on the issue of freedom of conscience of prisoners in Mexican prisons, a right of people which is violated by the programs of rehabilitation, social reintegration and related legislation, including some international legal instruments on human rights. Presents arguments designed to prove that both: the legal requirement of forced labor and the practice of diagnoses of personality, are transgressions of the right of prisoners to decide fundamental questions about life, subjective interest to be protected even during imprisonment.
\end{abstract}

Key words: prisons, human rights, freedom of conscience, social integration.

Por lo general, entre los derechos del ser humano el de la libertad suele ponderarse como uno de los más importantes debido a diferentes razones: ya sea porque representa una de las principales reivindicaciones del pensamiento liberal, por su orden de aparición entre los instrumentos internacionales en calidad de derecho de primera generación, o bien or la relevancia que se le ha concedido en la discusión teórica. ${ }^{2}$ No obstante, es pertinente hacer notar que las acciones humanas involucran un repertorio de experiencias y visiones del mundo tan diversas, que resulta ingenuo suponer que todas las personas comparten las mismas condiciones y capacidades para la práctica de su derecho a la libertad.

\footnotetext{
${ }^{*}$ Profesor Investigador de la Universidad Autónoma de la Ciudad de México y Catedrático del Instituto Nacional de Ciencias Penales.

${ }^{2}$ Por ejemplo, véase Rawls, John, La justicia como equidad, Paidós, 2002, pp. 18 y 19 y 147 y ss.; Teoría de la Justicia, Fonda de Cultura Económica, México, sexta reimpresión, pp. 192 y ss.; SEN, Amartya, Desarrollo y libertad, Planeta, México, 200o. pp. 86-89; Correas, Óscar, Acerca de los derechos humanos, Ediciones Coyoacán, México, 2003, pp. 149-153; Beuchot, Mauricio, Derechos humanos, historia y filosofía, Fontamara, México, 2001, pp. 9-19
} 
En tal sentido, puede destacarse cómo la privación de capacidades básicas, ${ }^{3}$ es decir, aquellas que permiten desarrollar el potencial del individuo para mejorar el nivel de calidad de su vida, tales como: la salud, el discernimiento, el pensamiento lógico, la expresión clara de ideas y sentimientos, el trato social solidario y la aptitud de asumir decisiones congruentes, influye de modo determinante en la competencia de los sujetos y de los grupos para ejercer la libertad. En otras palabras, la capacidad y el tipo de decisiones tomadas por alguien son un resultado de su cúmulo de conocimientos y experiencias - y de su estado de salud-, lo mismo que de las circunstancias en las cuales ha crecido y de aquellas que lo rodean.

Por ello, afirmar simplemente que todos somos iguales puede desmentirse desde una perspectiva no solamente económica, sino también desde las correspondientes a los ámbitos de carácter cultural, social y de vivencias propias de cada ser humano. Implica que aun cuando nuestras necesidades existenciales básicas nos igualan en la condición de seres humanos, la divergencia entre visiones del mundo, de oportunidades de acceso a la educación, la salud, el trabajo, vivienda y, en general, de satisfactores y experiencias, en cambio, nos distancian como individuos capaces de ejercer la libertad, por ejemplo, para decidir acerca de diferentes situaciones.

Ahora bien, en este asunto, dentro de la prisión se presenta una situación paradójica: en tanto que para los reclusos es necesario decidir por cuenta propia qué medidas les resultan indispensables o convenientes para mantenerse, no digamos equilibrados en su existencia, sino con vida, la absorbencia totalitaria de la institución los deteriora precisamente en aquello que más necesitan, que son sus capacidades de desempeño, incluida la de tomar decisiones. De ahí que sea un absurdo pretender reinsertar socialmente a alguien infligiendo severos ataques des-estructurantes a su identidad, es decir, a su integridad moral, psíquica, física y, en suma, a todo aquello que lo hace un individuo diferente, único entre los demás.

En efecto, la cárcel al mortificar y des-estructurar a los detenidos perjudica sus aptitudes para actuar en la vida. De modo que la libertad de un sujeto de pensar, expresarse, moverse, de elegir entre diversas alternativas que la vida le ofrece (es decir, su libertad de decidir ${ }^{4}$ y de conducirse en torno a su propia existencia), cuando ingresa en la prisión se ve seriamente circunscrita y disminuida por el régimen totalitario que sojuzga su singularidad.

Pero el hecho de que la uniformidad disciplinaria y la violencia autoritaria entorpezcan la capacidad del interno para tomar sus decisiones, no implica que alguien deba decidir por él y constreñir su voluntad, como sucede en el caso del tratamiento de rehabilitación que se le prescribe. Al contrario, significa que tales circunstancias necesariamente requieren ser modificadas y sustituidas con base en criterios guiados por el respeto a la dignidad humana, lo cual supone una concepción diferente de la organización penitenciaria.

Así, es preciso advertir que la libertad de decisión de los reclusos o autonomía de conciencia es inviolable. Por ello, en materia de derechos humanos y legislación, resulta asunto conflictivo el que dentro de tratados como el Pacto Internacional de Derechos Civiles y Políticos y la Convención Americana sobre Derechos Humanos, por citar sólo algunos, se permita lesionar la voluntad y por lo tanto la integridad de los individuos recluidos en una cárcel: $1^{\circ}$ al consentir la práctica del trabajo forzado cuando se impone como sanción penal

\footnotetext{
${ }^{3} \mathrm{Al}$ respecto de la pobreza como privación de capacidades, Vid., SEN, Amartya. op.cit., pp. 114-141.

${ }^{4}$ la cual, incluso en la vida exterior, se ejerce diferencialmente por los individuos de acuerdo con sus capacidades de actuación.
} 
$\operatorname{adjunta}^{5}$ (posibilidad que en nuestra constitución política se recoge en su artículo quinto $)$; y $2^{\circ}$ por considerar como parte del derecho a la integridad personal, a la finalidad de reforma y readaptación social de los condenados a la pena de prisión.

Esto revela cuánto ha llegado a valorarse moral, social y legalmente al trabajo como elemento formativo de la vida humana. Al grado de aceptar que aun cuando éste sea impuesto como actividad forzada, o se le prescriba como parte de un tratamiento presuntamente curativo o reformador, se le estime favorablemente para el objeto de incidir en el comportamiento de un condenado. Sin embargo, procede objetar que precisamente ante la obligación del Estado de preservar la integridad de quien está preso, no es admisible forzar su voluntad para trabajar o invadir la esfera de su intimidad con objeto de diagnosticarlo y determinarle un tratamiento, dado que toda acción o circunstancia que restrinja su posibilidad de decidir, resulta atentatoria a la integridad psíquica y moral del mismo.

Ciertamente, de acuerdo con la reflexión filosófica, la investigación teórica y las respectivas disposiciones jurídicas, los derechos de cualquier individuo son restringibles cuando como resultado de sus acciones se ven afectados los derechos de terceros; de ahí que la privación de la libertad se estime necesaria en muchos casos, junto con la limitación a otros derechos, para quien quebranta los de alguien más.

Pero una vez dentro de la prisión, el despojar a alguien de su libertad para tomar decisiones, lo cual se hace con los programas de tratamiento que buscan su rehabilitación social, no es humanística ni científicamente sostenible. Constituye una intromisión a la autonomía

\footnotetext{
${ }^{5}$ Vid. Pacto Internacional de Derechos Civiles y Políticos, Artículo $8^{\circ}$, numeral 3 incisos: “a) Nadie será constreñido a ejecutar un trabajo forzoso u obligatorio; b) El inciso precedente no podrá ser interpretado en el sentido de que prohíbe, en los países en los cuales ciertos delitos pueden ser castigados con la pena de prisión acompañada de trabajos forzados, el cumplimiento de una pena de trabajos forzados impuesta por un tribunal competente; c) no se considerarán como "trabajo forzoso u obligatorio", a los efectos de este párrafo: i) Los trabajos o servicios que, aparte de los mencionados en el inciso b, se exijan normalmente de una persona presa en virtud de una decisión judicial legalmente dictada (...)", y la Convención Americana sobre Derechos Humanos, Artículo 5. Derecho a la Integridad Personal. Numeral 6. "Las penas privativas de la libertad tendrán como finalidad esencial la reforma y la readaptación social de los condenados." Artículo 6. Prohibición de la Esclavitud y Servidumbre. Numeral 2. "Nadie debe ser constreñido a ejecutar un trabajo forzoso u obligatorio. En los países donde ciertos delitos tengan señalada pena privativa de la libertad acompañada de trabajos forzosos, esta disposición no podrá ser interpretada en el sentido de que prohíbe el cumplimiento de dicha pena impuesta por juez o tribunal competente. El trabajo forzoso no debe afectar la dignidad ni la capacidad física e intelectual del recluido." Numeral 3. "No constituyen trabajo forzoso u obligatorio, para los fines de este artículo: a) Los trabajos o servicios que se exijan normalmente de una persona recluida en cumplimiento de una sentencia o resolución formal dictada por la autoridad judicial competente. Tales trabajos o servicios deberán realizarse bajo la vigilancia y control de las autoridades públicas, y los individuos que los efectúen no serán puestos a disposición de particulares, compañías o personas jurídicas de carácter privado". Negritas puestas en esta investigación.

${ }^{6}$ Artículo 5, párrafo tercero: "Nadie podrá ser obligado a prestar trabajos personales sin la justa retribución y sin su pleno consentimiento, salvo el trabajo impuesto como pena por la autoridad judicial, el cual se ajustará a lo dispuesto en las fracciones I y II del artículo 123." Artículo 123, apartado A, fracción I: "La duración de la jornada máxima será de ocho horas;" fracción II:"La jornada máxima de trabajo nocturno será de siete horas. Quedan prohibidas: las labores insalubres o peligrosas, el trabajo nocturno industrial y todo otro trabajo después de las diez de la noche, de los menores de dieciséis años;" (negritas puestas en esta investigación). No obstante que la imposición del trabajo como pena por disposición judicial se intente apartar del trabajo forzoso, al condicionar el desempeño laboral a los términos del artículo 123, sólo se acota pero no se impide la eventualidad de forzar la voluntad de modo extremo: se restringe la duración de la jornada pero no se dice nada de su intensidad; y el prohibir los trabajos insalubres o peligrosos, y el industrial nocturno, no impide que cualquier otra labor pudiera llegar a ser inicua si las condiciones de su ejecución se manejan discrecionalmente por una autoridad proclive al abuso de poder, como la encargada de la prisión.
} 
de conciencia del detenido y, por consiguiente, una merma a su integridad psíquica y moral. En tal sentido, nadie, incluido el poder público, bajo ningún argumento presuntamente respetuoso y protector de los derechos a la libertad y a la integridad del ser humano, puede forzar la voluntad de otro e intervenir en su intimidad para, además, pretender modificar su estructura de pensamiento y aptitud volitiva. ${ }^{7}$

Así, respecto de los documentos internacionales citados, resulta irónico que en éstos se hagan excepciones violatorias al ejercicio de los derechos a la libertad e integridad de los individuos, al contravenir los de aquéllos que son prisioneros. En efecto, no es admisible que con la constricción del derecho a la libertad de tránsito, mediante la cárcel, también se limite la libertad de albedrío de los reclusos, pues, como vimos, esto constituye una agresión directa a su integridad y por ello una trasgresión al derecho que la reivindica, el cual no es alterable bajo ningún supuesto.

Por lo tanto, al no reparar en que el trabajo forzado y el tratamiento terapéutico son agresiones graves a la voluntad e integridad de los reclusos, y darle aval a dichas actividades, esos documentos incurren en una contradicción derivada en gran parte del anacronismo; antinomia posible de resolver por medio de una revisión que logre transformarlos, a fin constituir una directriz de mayor congruencia sobre definición y protección de los derechos humanos, es decir, que no violente los de individuos encerrados en la prisión.

Con el actual respaldo de los citados pactos internacionales, la autoridad penitenciaria violenta al recluso mediante la imposición de los estudios diagnósticos de personalidad y un tratamiento de readaptación -ahora llamada reinserción-, lo cual es una falta grave a su derecho a la libertad volitiva, no obstante ser acciones legales. Ello, en razón de que ninguna ley emitida dentro de un Estado de derecho (léase, Estado garantista), en calidad de garantía individual, puede considerarse como tal aunque esté vigente, si transgrede precisamente los derechos que debe tutelar. Esto significa que cualquier precepto legal que no cumpla con la única finalidad sólidamente justificadora de la existencia del derecho penal, a saber, la protección de los derechos humanos, es una ley inconsistente para el propósito de salvaguardar al individuo del abuso del poder público. ${ }^{8}$

En tal sentido, en México tanto el artículo 18 constitucional, lo mismo en su redacción anterior que en la vigente a partir del 18 de junio de 2008, como la Ley que establece las Normas Mínimas sobre Readaptación Social de Sentenciados (vigente en el ámbito federal desde 1971), y la Ley de Ejecución de Sanciones Penales para el Distrito Federal (vigente en la Ciudad de México desde 1999), al concebir al recluso como sujeto de tratamiento para su rehabilitación ${ }^{9}$ (llamarla readaptación o reinserción da igual, pues se conserva la visión

7 "Sobre sí mismo, sobre su mente", dice John Stuart Mill, "el individuo es soberano". Vid. Ferrajoli, Luigi, op.cit., p.272.

${ }^{8}$ Es decir, bajo la perspectiva de la teoría del garantismo penal, la existencia y el fin del derecho penal sólo se justifica como recurso para proteger a los individuos del abuso del poder del Estado. Respecto al garantismo penal como modelo normativo, teoría jurídica de la validez y la efectividad normativa, y como filosofía del derecho y crítica de la política, Vid. Ferrajoli, Luigi, Derecho y razón. Teoría del garantismo penal, op.cit. En particular, sobre la validez y la efectividad normativa, pp. 353-362, 852-853, 855-857,868-880.

${ }^{9}$ Constitución Política De Los Estados Unidos Mexicanos, Artículo18, $2^{\circ}$ párrafo: "El sistema penitenciario se organizará sobre la base del trabajo, la capacitación para el mismo, la educación, la salud y el deporte como medios para lograr la reinserción del sentenciado a la sociedad y procurar que no vuelva a delinquir..." Ley Que Establece Las Normas Mínimas Sobre Readaptación Social De Sentenciados, Artículo 2․ "El sistema penal se organizará sobre la base del trabajo, la capacitación para el mismo y la educación como medios para la readaptación social del delincuente." Ley De Ejecución De Sanciones Penales Para El Distrito Federal, Artículo 8. "La Subsecretaría, a través de la Dirección General, organizará las instituciones del Sistema Peni- 
terapéutica) se violentan varios de sus derechos, entre los que aquí se destaca el del libre albedrío, al someterlo, sin considerar su opinión, a un estudio para diagnosticarlo y tratarlo aun contra su voluntad.

$\mathrm{Al}$ respecto, no obstante que tanto en la ley de "Normas Mínimas" como en la de Ejecución de Sanciones Penales para el Distrito Federal, se estipula que al asignar trabajo a los internos se tomarán en cuenta "sus deseos, la vocación, las aptitudes" (Ley de "Normas Mínimas", Artículo 10)), así como "su interés" (Ley de Ejecución..., Artículo 14), el hecho de que esto sea parte de un tratamiento para el cual, en cambio, no se considera su punto de vista cuando se decide sujetarlos al mismo, involucra una imposición encubierta. Y en el mismo sentido, en la referida Ley de Ejecución de Sanciones, de forma también tácita, se establece la obligatoriedad del trabajo en los reclusos: "Artículo 15. No es indispensable el trabajo a: I quienes presenten alguna imposibilidad debidamente acreditada, ante el Consejo Técnico respectivo. II Las mujeres durante cuarenta y cinco días antes y después del parto. III Los indiciados, reclamados y procesados." ${ }^{10}$

Ahora bien, con relación al quebranto de varios derechos de los detenidos al someterlos a tratamiento de tipo terapéutico, conviene agregar lo siguiente:

$1^{\circ}$ De entrada, su presunción de inocencia es violentada dado que desde su ingreso se le somete a estudios de personalidad y se le diagnostica siempre como peligroso, ya sea en un bajo, medio o alto nivel y se le prescribe un tratamiento del cual el trabajo es parte. De este modo, el recluso, de inicio, aunque procesalmente aún no es determinada su responsabilidad del hecho que se le imputa, ya es peligroso y enfermo; dado que ha sido encasillado en una concepción clínica totalitaria en la que cualquiera es diagnosticado, en algún grado, con desequilibrios de personalidad. Nadie resulta sano en los estudios que se le practican, empero ¿quién va a conservar la salud íntegra, si acaso se posee, en ese entorno?

$2^{\circ}$ Todos los reclusos resultan con trastornos similares puesto que sus "perturbaciones" son formuladas en los mismos términos. Es decir, la visión totalitaria de la prisión prevaleciente entre el personal penitenciario, deviene en que cualquier detenido es acomodado a criterios de desequilibrio de personalidad -incluido el grado de su peligrosidad- formateados totalitariamente como instrumentos de diagnóstico. Bajo estas premisas, la totalidad de los internos se "ajusta" a una personalidad delincuencial que es una ficción sostenida en un terreno "clínico" penitenciario falsamente científico; y esto significa que los estudios que se les aplican son cooptados por una visión absorbente en la cual no cabe la individualización. Por ello nadie puede resultar sano, dado que todo el que entra ha sido sujeto de alguna imputación. Y en esto último está la visible falla: al recluido se le estudia "científicamente" con base en una imputación jurídica, la cual, dentro de la prisión, se traduce en la etiqueta de delincuente más o menos peligroso, pero siempre peligroso; de ningún modo sano de acuerdo al crimino-diagnóstico emitido, sobre todo, con sustento en este presupuesto más que mediante evidencias de carácter objetivo. De manera que su

tenciario del Distrito Federal, previendo que el proceso de readaptación de los internos se base en el trabajo, la capacitación para el mismo y la educación..."

${ }^{10}$ Ley De Ejecución De Sanciones Penales Para El Distrito Federal. Dentro de la mayor parte de las prisiones mexicanas el trabajo no es obligatorio para los internos, sin embargo, como se acaba de ver, el prescribirlo como elemento terapéutico es una forma de imposición a la voluntad del sujeto. 
personalidad se ajusta a lo que institucionalmente debe ser el perfil de un trastornado a quien es menester rehabilitar, sin la posibilidad de que sea de otro modo. Este es el objetivo primordial mediante el que se justifica la intervención en la intimidad y se fuerza la voluntad del sujeto a tratamiento.

Por último, procede hacer énfasis en que administrar un tratamiento penitenciario en las condiciones descritas constituye una falta grave a los derechos humanos de los detenidos. Es menester que cualquier programa aplicado dentro de la cárcel se dirija en sentido diferente. Uno que implique la conservación y equilibrio de los detenidos; que contemple su opinión y por lo mismo les ofrezca opciones a las cuales accedan en ejercicio de su libre albedrío. Cualquier imposición, directamente como sanción accesoria a la pena privativa de libertad, o indirectamente al prescribirse como parte de un tratamiento de orientación terapéutica, atenta contra el derecho a la libertad de decisión del detenido.

BIBLIOGRAFÍA

BEUCHOT, Mauricio, Derechos humanos, historia y filosofía, Fontamara, México, 2001.

CORREAS, Óscar, Acerca de los derechos humanos, Ediciones Coyoacán, México, 2003.

FERRAJOLI, Luigi, Derecho y razón. Teoría del Garantismo penal, Trotta, $9^{a}$ edición, Madrid, 2009.

RAWLS, John, La justicia como equidad, Paidós, Barcelona, 2002.

Teoría de la Justicia, Fondo de Cultura Económica, México, sexta reimpresión, 2006.

SEN, Amartya, Desarrollo y libertad, Planeta, México, 2000.

Documentos jurídicos

Constitución Política de los Estados Unidos Mexicanos.

Convención Americana sobre Derechos Humanos.

Ley que Establece las Normas Mínimas sobre Readaptación Social de Sentenciados.

Pacto Internacional de Derechos Civiles y Políticos.

Ley de Ejecución de Sanciones Penales para el Distrito Federal. 